\title{
Characterization and insecticidal activity of sucrose octanoates
}

\author{
Shujun LI*, Zijuan Song, Zhiming LIU, Songtao BAI \\ Key laboratory of Biobased material Science and technology of Ministry of Education, Northeast Forestry University, 26 Hexing Road, Harbin 150040, \\ People's Republic of China
}

(Accepted 16 August 2007)

\begin{abstract}
Sucrose esters, a new class of biopesticides related to the Nicotiana family, were synthesized efficiently under vacuum and isolated by column chromatography (CC). The isolations were characterized with mass spectrometry (MS) and nuclear magnetic resonance (NMR). Their insecticidal activities against Lymantria dispar grubs were determined. Thin-layer chromatography ultraviolet (TLC-UV) spectrophotometric analyses showed that the ratio of the monoesters to others in the reaction product was 1.48:1. After isolation by CC, three groups, which had polarity from weak to strong, were obtained in high purity. Both electrospray ionization (ESI)-MS and ${ }^{1} \mathrm{H}$ NMR analyses proved that these groups were triesters, diesters and monoesters, respectively. According to their peak areas of gas chromatographic (GC) analyses, the monoester content was $61.72 \%$. Among these esters, the reaction product and monoesters presented the highest insecticidal activities. The Lymantria dispar grub mortality reached $79.2 \%$ after being treated for 5 days with $12 \mathrm{mg} / \mathrm{mL}$ of the reaction products. The results indicate the synthesized sucrose octanoate product under vacuum is a good insecticide candidate.
\end{abstract}

Insecticidal activity / sucrose octanoate / isolation / characterization

\section{INTRODUCTION}

Plants are a natural source of biopesticides and bioherbicides such as eucalypt oil, mimosine and Petiveria alliacea extracts (Perez-Leala et al., 2005; Xuan et al., 2006; Batish et al., 2007). Sucrose fatty acid esters are non-toxic compounds that may be produced from renewable, economical and readily available resources. Free alcoholic hydroxyl groups of sucrose react with aliphatic or aromatic acids to produce sucrose esters. Sucrose esters have been commercially produced for the food industry. They are widely used in foods, cosmetics, agriculture and pharmaceuticals (Liu, 2001). Apart from their emulsifying properties, they are completely biodegradable, harmless to the environment, non-toxic, skin-compatible, odorless and tasteless. In 1984, sucrose esters were found in the cuticular waxes of a tobacco and have been related to aphid resistance and antifungal properties (Severion et al., 1984; Severson et al., 1985). Perhaps the most interesting plants are of the Nicotiana family, including Nicotiana tabacum and the commercial tobacco plant. Sucrose esters obtained from plants are composed of the lower fatty acids $\left(\mathrm{C}_{6}-\mathrm{C}_{12}\right)$ and possess very interesting biological properties (Arrendale et al., 1990; Puterka et al., 2003). The potent insecticidal activities of natural sucrose esters against persistent and damaging whiteflies have shown that sucrose esters are a new class of "natural" insecticides and should be exploited for commercial use (George et al., 1993; Farone et al., 2002, 2004). In addition, the toxicity of sucrose esters to some pests and safety for some beneficial insects were proved (Natwick, 1999; McKenzie and Puterka, 2004; McKenzie et al., 2004, 2005; Wadleigh et al., 2005;

*Corresponding author: lishujun_1999@yahoo.com
Parker et al., 2007; Michaud and McKenzie, 2004). Since the sucrose ester products are non-toxic to humans, crops and higher animals, fully biodegradable and hydrolyzed to readily metabolizable sucrose and fatty acid, they appear to be good insecticide candidates.

As the sucrose esters are produced in the glandular secretions of leaf hairs of Nicotiana plants (Fig. 1), their levels on those leaf surfaces are very small, being generally less than $100 \mu \mathrm{g} / \mathrm{cm}^{2}$ (Severson et al., 1991). Thus, natural plants will not likely become economical sources of millions of kilograms per year of sucrose esters to meet the demand for controlling whiteflies or aphids. Therefore, there is a need for a synthetic method for producing specific, biologically-active sucrose esters which have the capacity to control whiteflies and other soft-bodied arthropod pests. There are several methods for producing sucrose esters on an industrial scale, as developed by the food industry in the early 1960s. However, there are few reports about the synthesis of insecticidal sucrose esters and studies of their insecticidal activities. In our previous study, sucrose octanoate and caproate were synthesized (Li et al., 2005), and sucrose octanoates, which have the highest activity against a range of arthropod species (Puterka et al., 2003), were synthesized by a trans-esterification method under vacuum and the optimum reaction conditions were discussed (Song et al., 2006). Compared with other related studies (Chortyk, 1995, 2003; Liu et al., 1996; Chortyk et al., 1996; Xia et al., 1998), the synthesis method which was used has high efficacy and is safe for workers and friendly to the environment. In this report, the isolation, characterization and insecticidal activities of synthesized sucrose octanoates against Lymantria dispar $\mathrm{L}$. are described. 
(a)

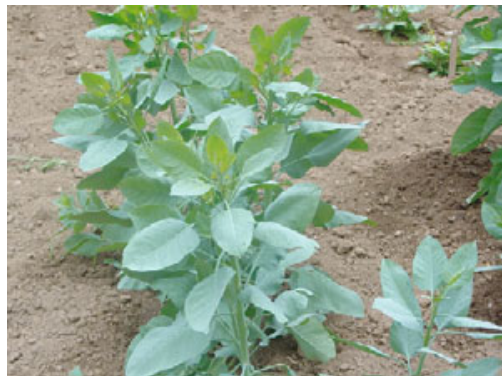

(b)

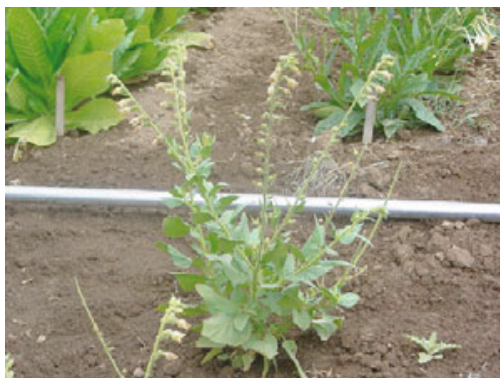

(c)

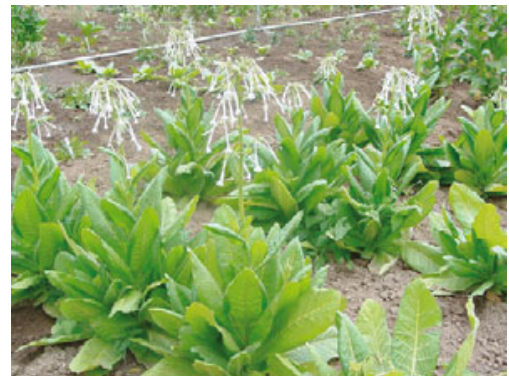

Figure 1. Several Nicotiana plants (http://www.uky.edu/Ag/Tobacco/N_Species/Photos-N_Species.htm). (a) Nicotiana glauca, (b) Nicotiana glutinosa, (c) Nicotiana sylvestris.

(a)

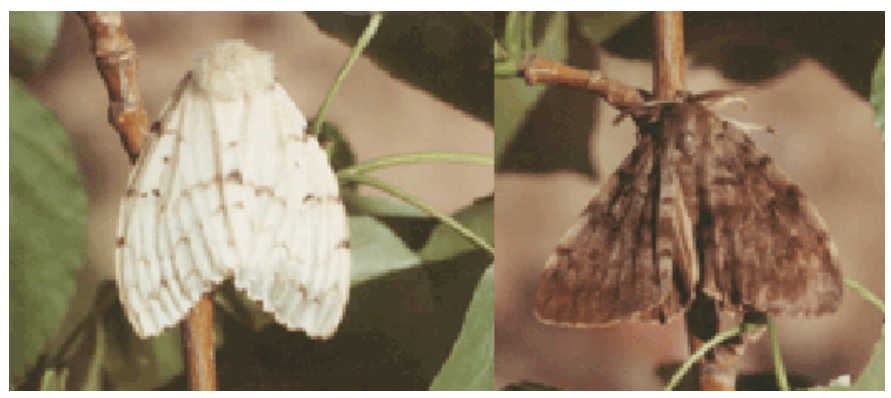

(b)

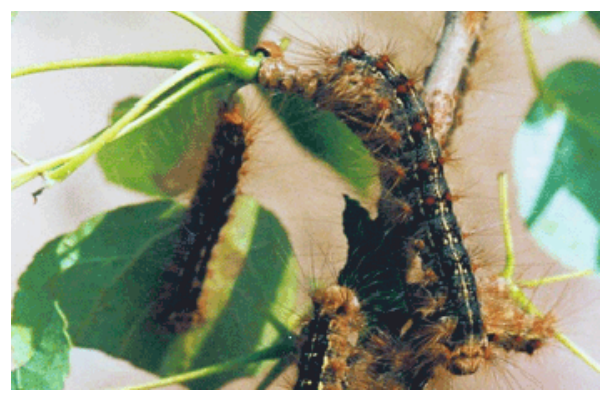

Figure 2. Lymantria dispar L. (http://www.nmsgsfz.com/articleview/2005-6-14/article_view_78.htm). (a) Imagoes, (b) grubs.

Lymantria dispar L. (Fig. 2) is a worldwide leaf-eating pest with a wide distribution and feeding source, and many host plants. This pest can injure many species of conifer and broadleaf, as well as some fruit tree species, and the destructive result is rather serious. In recent years, Lymantria dispar has been epidemic in the regions of Daxing'an Mountain in Inner Mongolia, China and the outbreak area has reached about $70000 \mathrm{hm}^{2}$ (Zang et al., 2005). The study of the efficacy of synthesized sucrose octanoates against it is also very meaningful for forest protection.

\section{MATERIALS AND METHODS}

\subsection{Sucrose octanoate synthesis}

Esterification was conducted in a dry flask with an electronic stirrer, a thermometer and a condensator. Sucrose was dissolved in dimethylsulfoxide (DMSO) at a certain concentration, with gentle heating and stirring until the sucrose dissolved. Then ethyl octanoate at a molar ratio to sucrose of 1:2 and $16 \%$ (w/w of ethyl octanoate) catalyst anhydrous $\mathrm{K}_{2} \mathrm{CO}_{3}$ were added, and the reaction mixture was stirred for $5 \mathrm{~h}$ at an absolute pressure of $11 \mathrm{kPa}$ and a temperature of $98 \pm 2{ }^{\circ} \mathrm{C}$ (Song et al., 2006). Once the reaction had been completed, the solvent was recovered by evaporating on a rotary evaporator under vacuum. The mixture was divided into two phases by the addition of $10 \%$ sodium chloride solution and $n$-butyl alcohol; one was a hydrophilic phase containing unreacted sucrose, the other was a lipophilic phase. The lipophilic phase was dried under vacuum, and then washed with ethyl acetate in order to dissolve the unreacted ethyl octanoate. The solution was dried under vacuum to eliminate the ethyl acetate (Liu, 1999). It was washed at least twice. The final product was obtained. The yield of $79.11 \%$ was calculated according to the following equation:

$$
\mathrm{YIELD}(\%)=\mathrm{W}_{\mathrm{A}} / \mathrm{W}_{\mathrm{T}} \times 100
$$

$\mathrm{W}_{\mathrm{A}}$ : Actual Weight of sucrose octanoate

$\mathrm{W}_{\mathrm{T}}$ : Theoretical Weight (Hypothetically, all the ethyl octanoate was used to produce monoesters of sucrose octanoate).

\subsection{Thin-layer chromatography (TLC) and spectrophotometric analyses}

As there are 8 hydroxyl groups in sucrose, numerous sucrose esters were yielded by esterification. The ultraviolet spectrum was used to determine the relative quantities of monoesters and polyesters after they were separated by TLC (Li et al., 2002). TLC was performed on silica gel plates. $\mathrm{SE}$ was dissolved in chloroform/methanol/water 1:1:0.2 (vol/vol/vol). Plates with spots were dipped in toluene/ethyl acetate/methanol/water 12:5:4.5:0.2 ( vol/vol/vol/vol); spots 
were detected by sprinkling the plate with carbamide phosphoric acid solution, drying and heating at $80{ }^{\circ} \mathrm{C}$ for $30 \mathrm{~min}$. UV spectra were recorded at $232 \mathrm{~nm}$ where the compounds had the maximum absorption abilities.

\subsection{Column chromatographic separation of sucrose octanoate on silica gel (CC)}

The reaction product, sucrose octanoates, dissolved in chloroform, were separated on activated silica gel using a solvent system of increasing percentages of methanol in methylene chloride. About $70 \mathrm{~g}$ of 200 mesh silica gel was required to separate about $3 \mathrm{~g}$ of reaction product. The silica gel, slurried in petroleum ether, was packed into a $40 \times 4 \mathrm{~cm}$ glass column. The reaction product was added to the top of the silica gel column. The column was eluted with $500 \mathrm{~mL}$ volumes of the following ratios of methylene chloride to methanol: 100:0, 100:2, 100:3, 100:4, 100:5, 100:6, 100:7, 100:8, 100:9, 100:10, 100:11, 100:12, 100:13, 100:14, 100:15, 100:16, 100:17 and 100:100. The resulting chromatographic fractions were collected and concentrated to dryness on a rotary evaporator $\left(40{ }^{\circ} \mathrm{C}\right)$ in round-bottom flasks. These fractions underwent TLC analysis and three of them with high purity were chosen for further analysis (Peterson et al., 1998). According their harvest orders, they were called Group 1, Group 2 and Group 3, respectively.

\subsection{Mass Spectrometric analyses}

Electrospray ionization - mass spectrometry (ESI-MS) was used to identify the three components. ESI-MS analyses were performed on an API-3000 LC-MS-MS spectrometer. MS conditions for analysis were: scan range of 400 900 m/z, 1.5 scans/s.

\subsection{Magnetic Resonance Spectrometric analyses}

${ }^{1} \mathrm{H}$ NMR spectra were recorded at $300 \mathrm{MHz}$ with a Bruker instrument, and reported with TMS as internal standard and DMSO- $d_{6}$ as solvent. Each separated group was in DMSO- $d_{6}$ solutions contained in $5 \mathrm{~mm}$ tubes. Chemical shifts ( $\delta$ values) were given in ppm.

\subsection{Sucrose ester GC analyses}

Gas Chromatographic analyses of the sucrose esters were performed on a Hewlett-Packard $6890+$ GC fitted with a DB$5(30 \mathrm{~m} \times 0.32 \mathrm{~mm})$ capillary column $(0.25 \mu \mathrm{m}$ film thickness); injector $280{ }^{\circ} \mathrm{C}$, oven $260{ }^{\circ} \mathrm{C}$. Sucrose esters were analyzed as their trimethylsilylated derivatives (TMS) prepared by reacting sucrose esters with hexamethyl-disilazane and trimethylchlorosilane for $6 \mathrm{~h}$ at $20^{\circ} \mathrm{C}$.

\subsection{Lymantria dispar grub bioassays}

4, 8 and $12 \mathrm{mg} / \mathrm{mL}$ aqueous dispersions of the total reaction product, sucrose octanoates, and each separated group were sprayed on Lymantria dispar grubs reared on the fresh leaves of aspen using an airbrush in some vessels. Each concentration was considered a treatment, and each treatment was replicated three times. The corrected mortality of Lymantria dispar grubs compared with water was recorded every $24 \mathrm{~h}$. The grubs were considered dead if no movement was detected when they were probed gently with a brush. The corrected mortality was calculated as follows (Eq. (2)):

$$
\text { Corrected mortality }(\%)=(\mathrm{X}-\mathrm{Y}) / \mathrm{X} \times 100
$$

$\mathrm{X}$ : non-mortality after treated by water,

Y: non-mortality after treated by sucrose octanoate.

\section{RESULTS AND DISCUSSION}

The continuing tranesterification was becoming more difficult after monoesters were produced. So less di-, tri- and other polyesters were obtained. Due to their lower quantity, these esters, except for monoesters, were combined to simplify the calculation. According to their UV absorption intensities, the molar ratio of monoesters and other esters was 1.48:1. By column chromatograph separation and elution with increasing percentages of methanol in methylene chloride, three groups with high purity were obtained. Speculatively, they were triesters, diesters and monoesters, respectively. These three groups underwent ESI-MS analyses and their spectra are shown in Figure 3. Electrospray is a technique where droplets are generated when a high voltage is applied to a liquid stream. In the electrospray process, a population of variably-charged ions are generated (Cole, 1997). In this report, the population mainly contained $[\mathrm{M}+\mathrm{H}]^{+},[\mathrm{M}+\mathrm{Na}]^{+}$or $[\mathrm{M}+\mathrm{K}]^{+}$. The intensity of the peaks is a reflection of the population generated in the electrospray process. In the spectrum of Group 1, m/z of 743.3 is equal to the molecular weight of triesters plus $\mathrm{Na}^{+}$, while 759.4 is equal to that of triesters plus $\mathrm{K}^{+}$; In the spectra of Group 2 and Group 3, m/z of 617.6 is from diesters plus $\mathrm{Na}^{+}$ and $\mathrm{m} / \mathrm{z}$ of 491.2 is from monoesters plus $\mathrm{Na}^{+}$. These ESI-MS spectra indicate that Groups 1,2 and 3 are mainly triesters, diesters and monoesters, respectively. This result is the same as that speculated.

The $\delta$ values of ${ }^{1} \mathrm{H}$ NMR spectra (see Fig. 4) are shown in Table I. The spectrum of each group showed the characteristic proton peaks. According to these spectra, Group 1 had three $\left(\mathrm{CH}_{3}-\left(\mathrm{CH}_{2}\right)_{5}^{-}\right)$groups and three $\left(-\mathrm{CH}_{2} \mathrm{COO}-\right)$ groups while Group 2 had two of both and Group 3 had one. Clearly, they were triesters, diesters and monoesters, respectively.

After the ESI-MS and NMR analyses, the three groups of isolates were identified. Then their relative contents were determined with GC. The spectra of the three isolates and the product, sucrose octanoates, are shown in Figure 5. According to these spectra, $R_{f}$ of the monoesters is less than $12.5 \mathrm{~min}$ while $R_{f}$ of the diesters is greater than 22.5 min and $R_{f}$ of the triesters is greater than $15 \mathrm{~min}$ and less than $22.5 \mathrm{~min}$. By calculating on the basis of peak area, the monoester relative content was $61.72 \%$, which was almost the same as the result of TLC-UV analyses.

Bioassays of the reaction product, sucrose octanoates, and each isolate, were conducted on the Lymantria dispar grubs 

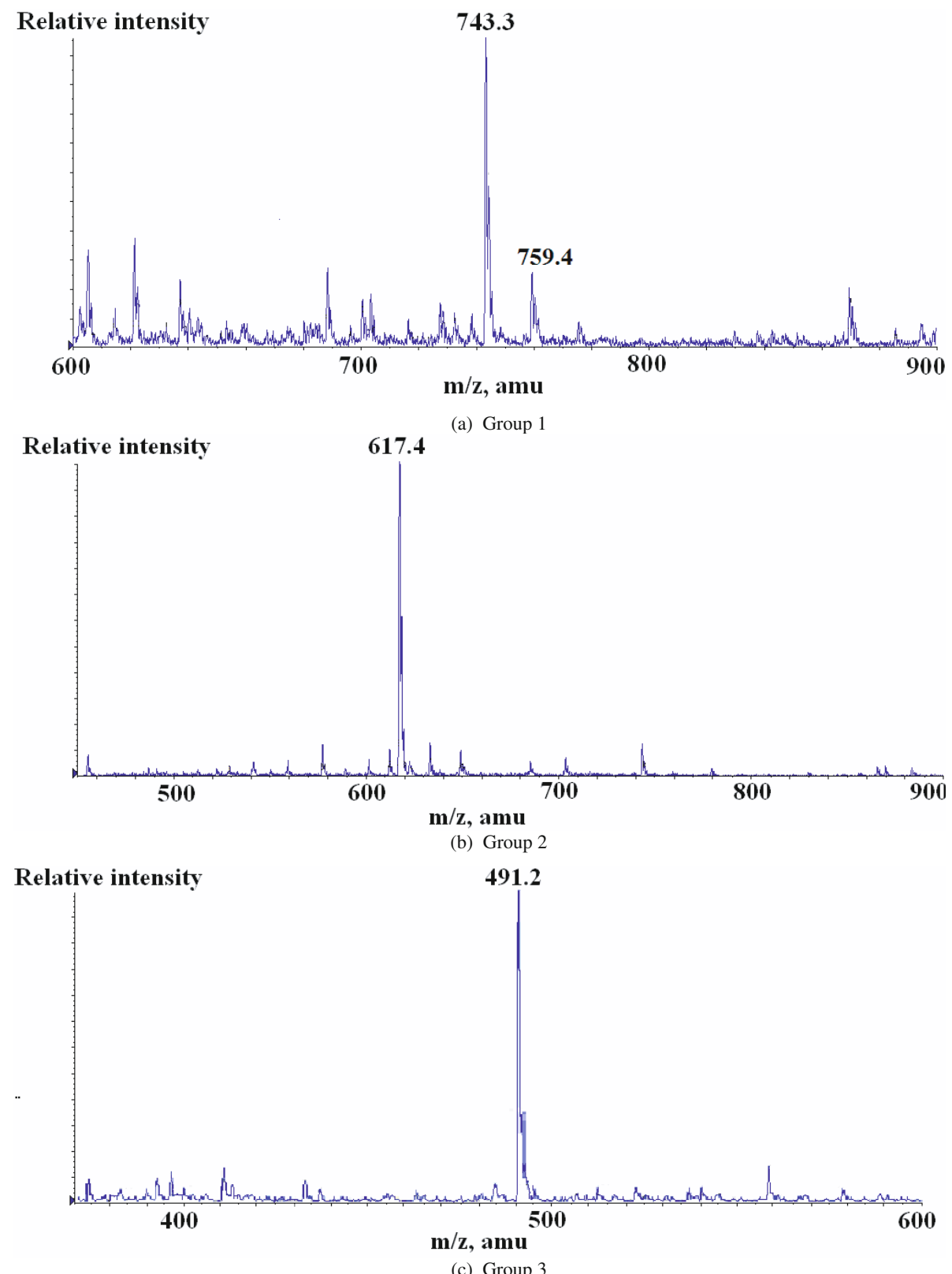

Figure 3. Electrospray ionization - mass spectrometric (ESI-MS) spectra of three isolates. 743.3, 617.6 and 491.2 are equal to the molecular weight of triesters, diesters and monoesters plus $\mathrm{Na}^{+}$, respectively. This indicates the three compounds are mainly triesters, diesters and monoesters.

Table I. ${ }^{1} \mathrm{H}$ NMR Shift ( $\delta$ ) Data for Major Synthetic Sucrose Octanoate.

\begin{tabular}{lccr}
\hline & Group 1 & Group 2 & Group 3 \\
\hline $\mathrm{CH}_{3}{ }^{-}$ & 0.86 & 0.85 & 0.85 \\
$-\left(\mathrm{CH}_{2}\right)^{-}$ & 1.25 & 1.24 & 1.25 \\
$-\mathrm{CH}_{2} \mathrm{COO}-$ & 2.31 & 2.30 & 2.30 \\
$\mathrm{O}-\mathrm{CH}-\mathrm{O}$ & 5.30 & 5.30 & 5.31 \\
$\mathrm{Glc} \mathrm{H}$ & $3.47 \sim 5.30$ & $3.46 \sim 5.30$ & $3.57 \sim 5.31$ \\
$\mathrm{Frc} \mathrm{H}$ & $3.50 \sim 4.32$ & $3.70 \sim 4.25$ & $3.57 \sim 4.17$ \\
$\mathrm{OH}$ & $3.15 \sim 5.70$ & $3.10 \sim 5.40$ & $3.20 \sim 5.50$ \\
\hline
\end{tabular}




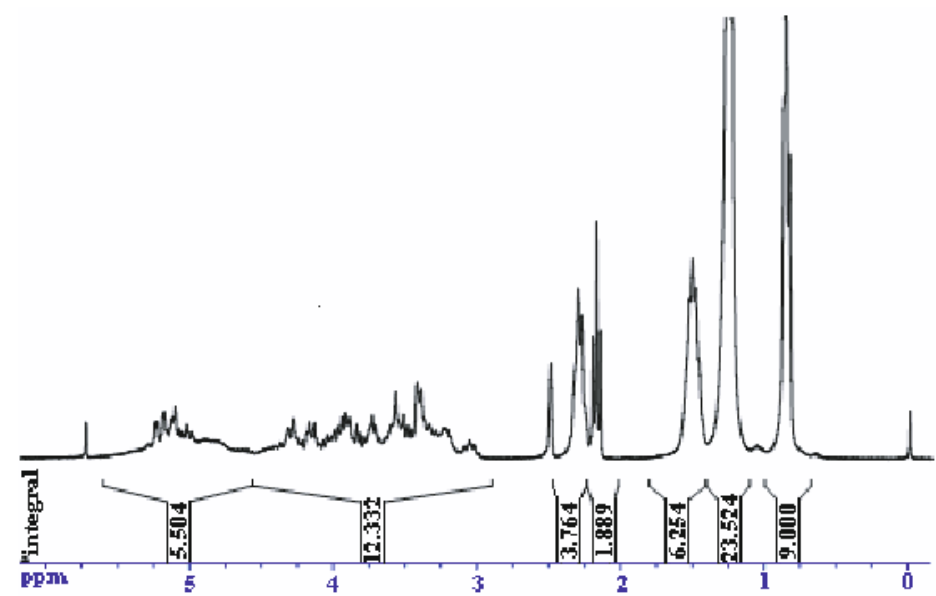

(a) Group 1

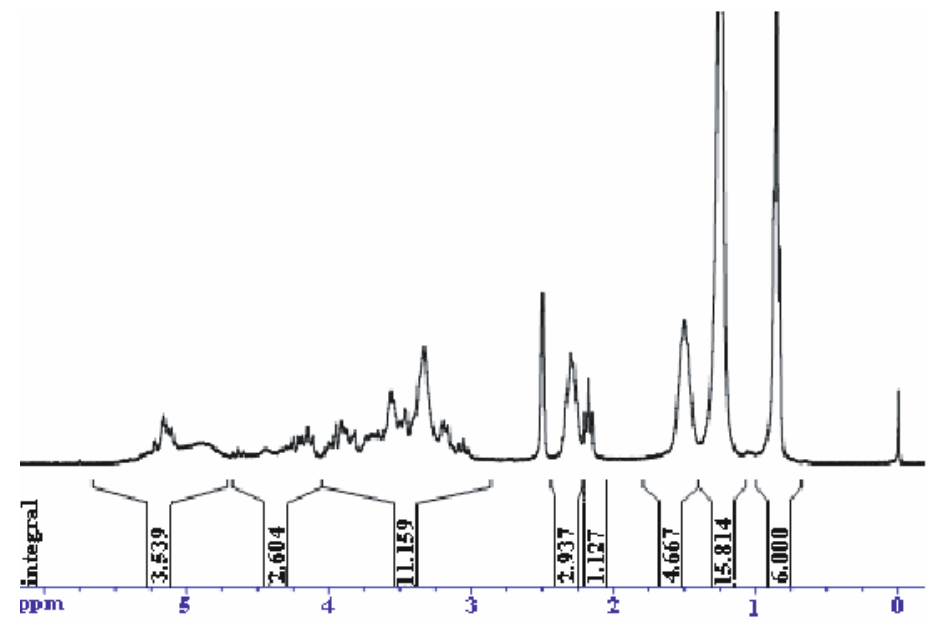

(b) Group 2

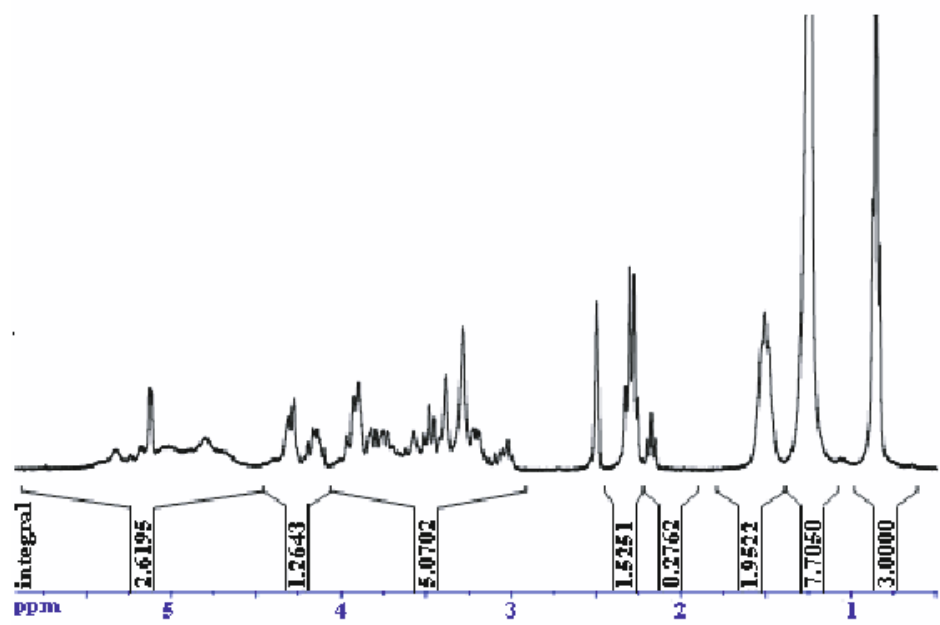

(c) Group 3

Figure 4. ${ }^{1} \mathrm{H}$ nuclear magnetic resonance (NMR) spectrometric spectra of three isolates. According to the shift data and integral, Group 1 had three $\left(\mathrm{CH}_{3}-\left(\mathrm{CH}_{2}\right)_{5^{-}}\right)$groups and three (- $\left.\mathrm{CH}_{2} \mathrm{COO}-\right)$ groups, Group 2 had two of both, and Group 3 had only one of each group. That suggests that the three compounds were triesters, diesters and monoesters, respectively. 
Table II. The corrected mortality of Lymantria dispar grubs from the different sucrose octanoates.

\begin{tabular}{|c|c|c|c|c|c|c|c|c|}
\hline & \multirow{2}{*}{$\begin{array}{l}\text { concentration/ } \\
(\mathrm{mg} / \mathrm{mL})\end{array}$} & \multirow[b]{2}{*}{$1 \mathrm{~d}$} & \multicolumn{3}{|c|}{ number of deaths } & \multirow[b]{2}{*}{$5 \mathrm{~d}$} & \multirow{2}{*}{$\begin{array}{l}\text { final } \\
\text { mortality } / \%\end{array}$} & \multirow{2}{*}{$\begin{array}{l}\text { corrected } \\
\text { mortality } / \%\end{array}$} \\
\hline & & & $2 \mathrm{~d}$ & $3 d$ & $4 d$ & & & \\
\hline & 4 & 7 & 2 & 0 & 0 & 5 & 56.0 & 54.2 \\
\hline \multirow[t]{3}{*}{ reaction product } & 8 & 7 & 0 & 2 & 6 & 1 & 64.0 & 62.5 \\
\hline & 12 & 9 & 4 & 2 & 3 & 2 & 80.0 & 79.2 \\
\hline & 4 & 3 & 2 & 2 & 1 & 4 & 48.0 & 45.8 \\
\hline \multirow[t]{3}{*}{ monoesters } & 8 & 3 & 1 & 3 & 9 & 5 & 84.0 & 83.3 \\
\hline & 12 & 2 & 1 & 3 & 10 & 3 & 76.0 & 72.9 \\
\hline & 4 & 1 & 1 & 3 & 3 & 5 & 48.0 & 45.8 \\
\hline \multirow[t]{3}{*}{ diesters } & 8 & 4 & 3 & 2 & 2 & 3 & 56.0 & 54.2 \\
\hline & 12 & 9 & 3 & 1 & 1 & 3 & 68.0 & 66.7 \\
\hline & 4 & 1 & 0 & 4 & 3 & 3 & 44.0 & 41.7 \\
\hline \multirow[t]{2}{*}{ triesters } & 8 & 0 & 1 & 3 & 5 & 3 & 48.0 & 45.8 \\
\hline & 12 & 0 & 2 & 2 & 6 & 3 & 52.0 & 50.0 \\
\hline control (water) & 0 & 0 & 0 & 0 & 1 & 0 & 4.0 & - \\
\hline
\end{tabular}
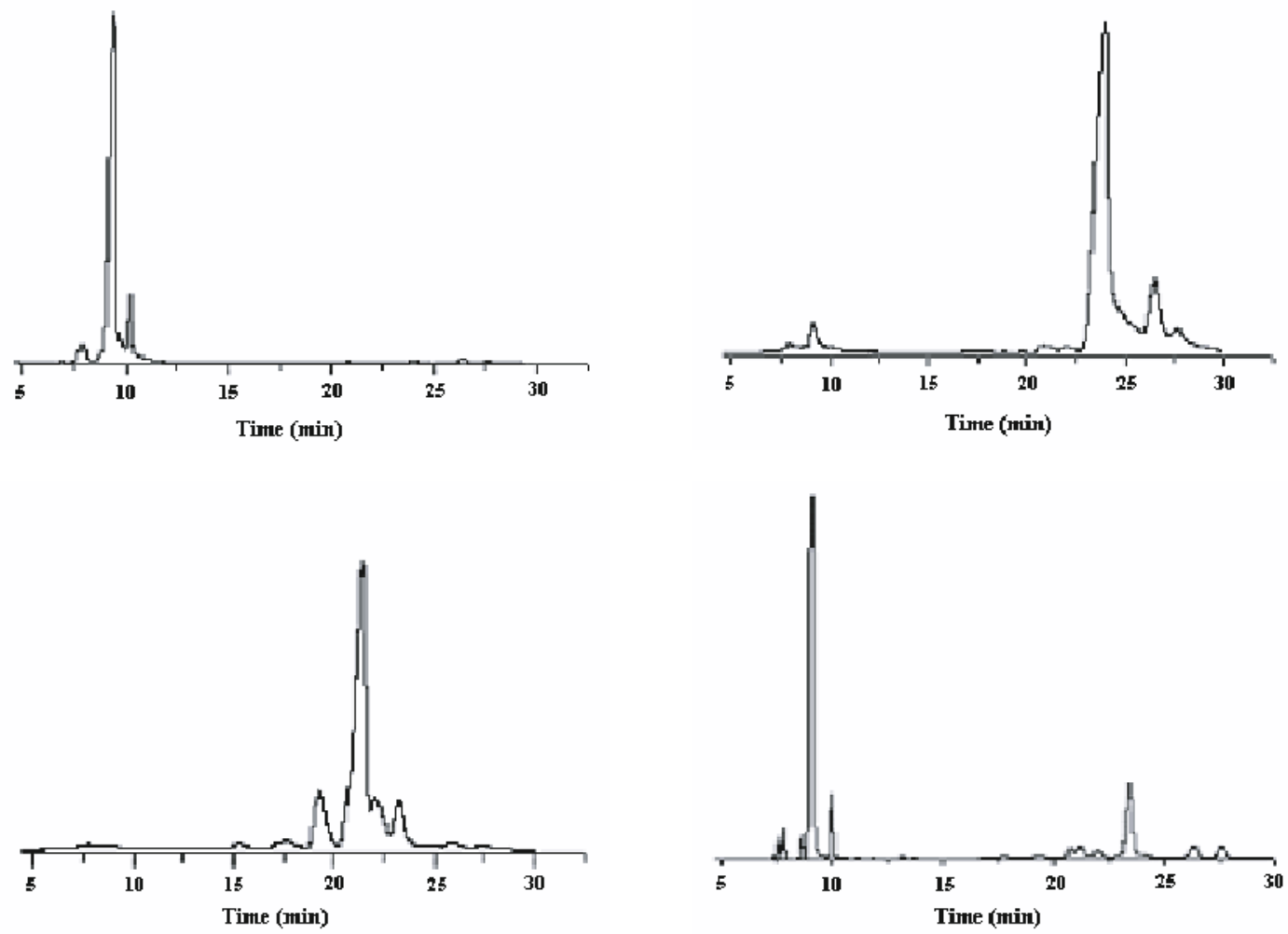

Figure 5. Gas chromatographic (GC) spectra. $R_{\mathrm{f}}$ of the monoesters is less than $12.5 \mathrm{~min}, \mathrm{R}_{\mathrm{f}}$ of the diesters is greater than 22.5 min, while $\mathrm{R}_{\mathrm{f}}$ of the triesters is greater than $15 \mathrm{~min}$ and less than $22.5 \mathrm{~min}$. According to their peak areas, the monoester relative content was $61.72 \%$. (a) Trimethylsilylated derivative of the monoesters, (b) Trimethylsilylated derivative of the diesters, (c) Trimethylsilylated derivative of the triesters, (d) Trimethylsilylated derivatives of the reaction product.

(Tab. II). At $4 \mathrm{mg} / \mathrm{mL}$, mono-, di- and triesters showed a similar corrected mortality against Lymantria dispar grubs. However, the reaction product and monoesters presented the highest mortality with increasing ester concentration. It is also expected that higher concentrations would yield high toxicities against soft-bodied arthropods. The mortality reached $79.2 \%$ after being treated for 5 days with $12 \%$ of the reaction products, which indicates that sucrose octanoates are potent pesticides against Lymantria dispar grubs.

\section{CONCLUSION}

Sucrose esters, which were synthesized under vacuum, were isolated by column chromatography and identified by many methods. TLC-UV analyses showed that the ratio of the monoesters to other esters in the reaction product was 1.48:1. After isolation with $\mathrm{CC}$, three groups, which had polarity from weak to strong, were obtained in high purity. Both ESI-MS and ${ }^{1} \mathrm{H}$ NMR analyses proved these groups were triesters, diesters 
and monoesters, respectively. With these pieces of information, the monoester content was calculated to be $61.72 \%$ with $\mathrm{GC}$ analyses on the basis of peak area. Lymantria dispar grub bioassays showed that the reaction product and monoesters presented the highest mortality among these esters. The mortality reached $79.2 \%$ after being treated for 5 days with $12 \%$ of the reaction products. Since the sucrose octanoates are nontoxic to humans, crops and higher animals, fully biodegradable and hydrolyzed to readily metabolizable sucrose and fatty acid, they appear to be good insecticide candidates.

Acknowledgements: We acknowledge support from the Post-doctoral Fund of Heilongjiang Province (LBH-Q05009), the Program for Tackling Key Problems of Heilongiiang Province (GB06B304-7), China, and also Beth Arends and Dr. Joe Karchesy for his valuable suggestions.

\section{REFERENCES}

Arrendale R.F., Severson R.F., Sisson V.A., et al. (1990) Characterization of the sucrose ester fraction from nicotiana glutinosa, J. Agr. Food Chem. 38, 75-85.

Daizy Rani Batish, Harminder Pal Singh, Nidhi Setia, Ravinder Kumar Kohli, b, Shalinder Kaur and Surender Singh Yadav (2007) Alternative control of littleseed canary grass using eucalypt oil, Agron. Sustain. Dev. 27, 171-177, DOI: 10.1051/agro:2007008.

Chortyk O.T. (1995) Syntheses and pesticidal activities of new sucrose esters, 21th ACS National Meeting, Chicago 210, 20-24.

Chortyk O.T., Pomonis J.G., Johnson A.W. (1996) Syntheses and Characterizations of Insecticidal Sucrose Esters, J. Agr. Food Chem. 44, 1551-1557.

Chortyk O.T. (2003) Chemically synthesized sugar esters for the control of soft-bodied orthropods, US, 6608039.

Cole R.B. (1997) Electrospray Ionization Mass Spectrometry: fundamentals, instrument and applications, John Wiley \& Sons, New York, USA, pp. 175-177.

Farone W.A., Palmer T., Puterka G.J. (2002) Polyol ester insecticides and method of synthesis, US, 6419941.

Farone W.A., Palmer T., Puterka G.J. (2004) Polyol ester insecticides, US, 6756046.

George W., Hyattsville P., Buta J.G., et al. (1993) Biological pesticide derived from nicotiana plants. US, 5260281.

Li S., Song Z., Chen X., et al. (2005) Synthesis of insecticidal sucrose esters, Jingxi Huagong(Ch). 56-58.

Li Y., Zhang S., Yang J. (2002) Analysis of sucrose ester by thin-layer chromatography, Chinese J. Chromatography 20, 476-478.

Liu T., Stansly P.A., Chortyk O.T. (1996) Insecticidal activity of natural and synthetic sugar esters against Bemisia argentifolii (Homoptera: Aleyrodidae), J. Econo. Entomol. 89, 1233-1239.

Liu X., He G., Yuan C., et al. (2001) Advance in research, production and application of sucrose ester, Food Fermentation Ind. 27, 64-70.
Liu Z. (1999) Study on purification of sucrose esters, J. Wuhan Polytech. Univ. 3, 11-14.

McKenzie C.L., Puterka G.J. (2004) Effect of sucrose octanoate on survival of nymphal and adult Diaphorina citri (Homoptera: Psyllidae), J. Econ. Entomol. 97, 970-975.

McKenzie C.L., Weathersbee A.A. III, Hunter Wayne, et al. (2004) Sucrose octanoate toxicity to brown citrus aphid(Homoptera: Aphididae) and the parasitoid Lysiphlebus testaceipes (Hymenoptera: Aphidiidae), J. Econ. Entomol. 97, 1233-1238.

McKenzie C.L., Weathersbee A.A. III, Puterka G.J. (2005) Toxicity of sucrose octanoate to egg, nymphal, and adult Bemisia tabaci (Hemiptera: Aleyrodidae) using a novel plant-based bioassay, J. Econ. Entomol. 98, 1242-1247.

Michaud J.P., McKenzie C.L. (2004) Safety of a novel insecticide, sucrose octanoate, to beneficial insects in Florida citrus, Florida Entomol. 87, 6-9.

Natwick E.T. (1999) New insecticides for control of silverleat whitefly: an efficacy evaluation, Proceedings-Beltwide Cotton Conferences, pp. 919-921.

Parker D.L. Wilson, Cameron D., Puritch, George S., et al. (2007) Wide-spectrum insecticidal and acaricidal composition, WO, 2007031561

Pérez-Leal R., García-Mateos M.R., Vásquez-Rojas T.R., Colinas-León M.T. (2005) Agron. Sustain. Dev. 25, 177-182, Allelopathic potential of Petiveria alliacea L., DOI: 10.1051/agro:2005015.

Peterson J.K., Snook M.E., Harrison H.F., et al. (1998) Isolation and structural identification of sucrose esters from corn spurrey (Spergula arvensis); inhibition of seed germination, J. Chem. Ecol. 24, 1803-1807.

Puterka G.J., Farone W., Palmer T., et al. (2003) Structure-function relationships affecting the insecticidal and miticidal activity of sugar esters, J. Econ. Entomol. 96, 636-644.

Severion R.F., Arrendile R.F., Chortyk O.T., et al. (1984) Quantitation of the major cuticular components from green leaf of different tobacco types, J. Agr. Food Chem. 32, 566-570.

Severson R.F., Arrendale R.F., Chortyk O.T., et al. (1985) Isolation and characterization of the sucrose esters of the cuticular waxes of green tobacco leaf, J. Agr. Food Chem. 33, 870-875.

Severson R.F., Jackson D.M., Johnson A.W., et al. (1991) Ovipositional behavior of tobacco budworm and tobacco hornworm, in Naturally Occurring Pest Bioregulators, 264-277.

Song Z., Li S., Chen X., et al. (2006) Synthesis of insecticidal sucrose esters, For. Stud. China 8, 26-29.

Wadleigh R.W., Perry R.E., Schroeder P.J. (2005) Methods for using polyol esters to control pests, US, 2005197317.

Xia Y., Johnson A.W., Chortyk O.T. (1998) Toxicity of synthetic sucrose esters against the tobacco aphid (Homoptera: Aphididae), J. Entomol. Sci. 33, 292-299.

Xuan T.D., Elzaawely A.A., Deba F., Fukuta M., Tawata S. (2006) Mimosine in Leucaena as a potent bio-herbicide, Agron. Sustain. Dev. 26, 89-97, DOI: 10.1051/agro:2006001.

Zang G., Wang Y., Yang X. (2005) Control of Lymantria dispar L. by biological agents, J. For. Res. 16, 158-160. 